\title{
Prevalence of Cigarette Smoking and Associated Factors among Residents of Hossana Town, Southern Ethiopia
}

\author{
Abera Beyamo Mekiso $(D$, Temesgen Tamirat Fonkamo, Tekle Ejajo Wontamo, \\ Fitsum Endale Liben, Ermias Abera Turuse, Aregash Mecha Watumo, \\ Lonsako Abute Woiloro $\mathbb{D}$, Dawit Sullamo Erjino $\mathbb{D}$, Tegegn Tadesse Arficho, \\ and Dejene Ermias Mekengo
}

School of Public Health, College of Medicine and Health Sciences, Wachemo University, Hosaena, Ethiopia

Correspondence should be addressed to Abera Beyamo Mekiso; bdereje05@gmail.com

Received 25 September 2021; Accepted 7 January 2022; Published 20 January 2022

Academic Editor: Narsingh Verma

Copyright ( 92022 Abera Beyamo Mekiso et al. This is an open access article distributed under the Creative Commons Attribution License, which permits unrestricted use, distribution, and reproduction in any medium, provided the original work is properly cited.

\begin{abstract}
Background. Tobacco is the only legal product that kills a large number of its consumers when used as intended by producers. Information on cigarette smoking and associated factors among adults at the household level is very limited. Objective. To assess prevalence of cigarette smoking and associated factors among residents of Hossana town, Hadiya zone, Southern Ethiopia, 2020. Methods and Materials. A cross-sectional study design was performed. A structured questionnaire was used to collect data. Bivariate and multivariable binary logistic regression was used to identify risk factors of cigarette smoking. Variables significant at a $p$ value of less than 0.05 were considered as independent predictors. Hosmer and Lemeshow test statistics were done to test the model fitness for the final model. Similarly, multicollinearity was checked by using collinearity statistics (tolerance and VIf). Result. In total, 591 people responded to the survey, resulting in a 98.2\% response rate. Among the study participants, cigarette smokers were $183(31.0 \%)$. Educational status, alcohol use, and parental smoking were all found to have a significant relationship with cigarette smoking among research participants in Hosanna town. When compared to people with a college education or above, illiterates are approximately nine times more likely to consume cigarettes (95\% CI $=9.058(3.52,22.469))$. Alcoholics are about twice as likely as nondrinkers to smoke cigarettes $(95 \% \mathrm{CI}=2.288(1.548,3.383))$. Those who have cigarette-smoking parents are approximately twice as likely as their counterparts to smoke cigarettes (95\% CI $=2.288(1.548,3.383))$. Conclusion. According to this survey, the prevalence of cigarette smoking was high. Furthermore, cigarette smoking was linked to illiteracy, alcohol consumption, and parental smoking in this study.
\end{abstract}

\section{Background}

When used as intended by makers, tobacco is the only allowed product that kills a considerable number of its customers. Tobacco is available in both smoked and nonsmoked forms. Tobacco is smoked in a variety of ways, including cigarettes (made or hand-rolled), cigars, pipes, and water pipes. Manufactured cigarettes are the most extensively used smoked tobacco product on the globe $[1,2]$.

Tobacco usage is linked to six of the world's eight main causes of mortality. Tobacco use causes lung cancer, laryngeal cancer, kidney cancer, bladder cancer, stomach cancer, colon cancer, oral cancer, and esophageal cancer, as well as leukemia, chronic bronchitis, chronic obstructive pulmonary disease, ischemic heart disease, stroke, miscarriage and premature birth, birth defects, and infertility $[1,3]$.

Tobacco continues to be a global health pandemic, killing around 6 million people each year and incurring hundreds of billions of dollars in annual financial losses [4].

Tobacco smoke contains about 7000 synthetic chemicals and substances. Hundreds are hazardous, and more than 70 cause diseases such as cancer. Exposure to smokers (friends, 
TABLE 1: Socio-demographic characteristics of study participants in Hossana town, 2019/2020.

\begin{tabular}{|c|c|c|c|}
\hline Variable & Category & Number & Percent (\%) \\
\hline \multirow{4}{*}{ Age } & $18-27$ years & 261 & 44.2 \\
\hline & $28-37$ years & 161 & 27.2 \\
\hline & $38-47$ years & 163 & 27.6 \\
\hline & $\geq 48$ & 6 & 1.0 \\
\hline \multirow{2}{*}{ Sex } & Male & 504 & 85.3 \\
\hline & Female & 87 & 14.7 \\
\hline \multirow{4}{*}{ Marital status } & Single & 165 & 27.9 \\
\hline & Married & 408 & 69.0 \\
\hline & Divorced & 7 & 1.2 \\
\hline & Widowed & 11 & 1.9 \\
\hline \multirow{4}{*}{ Family size } & $1-3$ & 165 & 27.9 \\
\hline & $4-6$ & 347 & 58.7 \\
\hline & $7-8$ & 7.6 & 7.6 \\
\hline & $\geq 8$ & 5.8 & 5.8 \\
\hline \multirow{4}{*}{ Religion } & Protestant & 269 & 45.5 \\
\hline & Orthodox & 245 & 41.5 \\
\hline & Muslim & 47 & 8.0 \\
\hline & Catholic & 30 & 5.1 \\
\hline \multirow{6}{*}{ Ethnicity } & Hadiya & 251 & 42.5 \\
\hline & Kembata & 191 & 32.3 \\
\hline & Gurage & 70 & 11.8 \\
\hline & Silte & 44 & 7.4 \\
\hline & Amhara & 16 & 2.7 \\
\hline & Wolaita & 19 & 3.2 \\
\hline \multirow{7}{*}{ Occupation } & Daily laborer & 217 & 36.7 \\
\hline & Gov't employed & 208 & 35.2 \\
\hline & Self-employed & 72 & 12.5 \\
\hline & Student & 6 & 1 \\
\hline & Housewife & 5 & 0.8 \\
\hline & No job & 3 & 0.5 \\
\hline & Merchant & 80 & 13.5 \\
\hline \multirow{3}{*}{ Educational status } & Illiterate & 161 & 27.2 \\
\hline & $\leq 12$ grade & 371 & 62.8 \\
\hline & $\geq$ College & 59 & 10.0 \\
\hline \multirow{5}{*}{ Monthly income } & 0-1500 & 83 & 14.0 \\
\hline & $1501-3000$ & 86 & 14.6 \\
\hline & $3001-4500$ & 155 & 26.2 \\
\hline & $4501-6000$ & 88 & 14.9 \\
\hline & $\geq 6001$ & 179 & 30.3 \\
\hline
\end{tabular}

parents, and instructors), nicotine availability, low socioeconomic level, poor academic achievement, low self-esteem, and a lack of skill to prevent tobacco use are all factors linked to teenage cigarette smoking [5-7].

In 2013, 22 percent of the world's population aged 15 and up, including 36 percent of men and $8 \%$ of women [7], were predicted to smoke cigarettes, and by 2025, approximately 1.6 billion people are expected to be cigarette smokers [8]. Women in upper middle and higher income

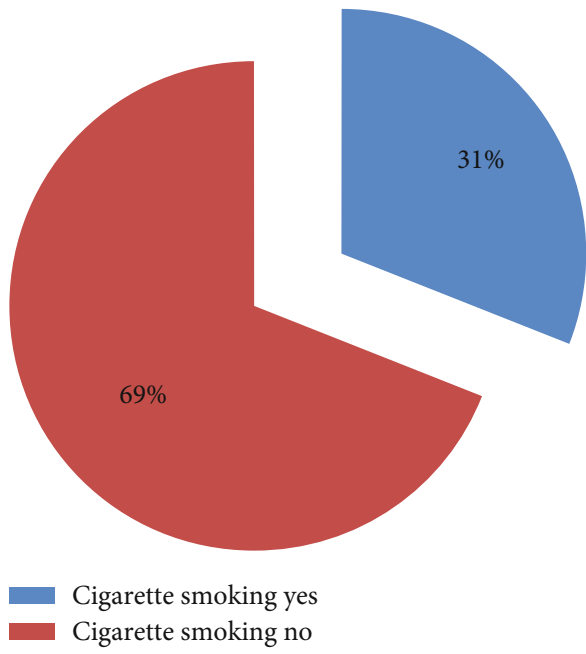

Figure 1: Prevalence of cigarette smoking among study participants in Hosanna town, Southern Ethiopia, 2019/20.

countries smoke more cigarettes than women in poor and lower-middle income countries [9].

The majority of smokers (89\%) start smoking before they reach the age of 19 , when they are still living with their parents $[5,10-12]$. The findings reveal that starting to smoke at a younger age is linked to smoking more cigarettes per day later in life than starting at an older age, implying that postponing the initiation of smoking may affect the chance of becoming addicted to cigarettes [13]. There are many potential environmental exposure sites for cigarette smoking: public places, retail shops, and smoking in cars and home. Among which home was identified as the potential environmental exposure site (second hand smoking) to children and adults as well as potential for youth's initiation [14-17].

The Framework Convention on Tobacco Control (WHO FCTC) of the World Health Organization recognizes the significant impact of tobacco use and the urgent need to avoid it $[4,18]$. In contrast to past drug control treaties, the WHO FCTC is an evidence-based treaty that aids in the development of a regulatory plan to handle addictive substances. It highlights the relevance of demand and supply reduction methods. [18]

But according to the investigators knowledge, information on prevalence and factors that influence it is extremely rare in low and middle income countries, particularly Ethiopia. As a result, the purpose of this study is to determine the prevalence of cigarette smoking in Hossana, Ethiopia, as well as the factors that influence it.

\section{Methods}

2.1. Study Design and Area. A community-based cross sectional study design was conducted among residents in Hadiya zone, Hossana town, from April 01 to 30, 2020. Hossana town is located at $230 \mathrm{~km}$ South of Addis Ababa. According to the 2007 national census, the projected total population of the town is $108,428(53,129$ males ad 55,299 females). The total number of HHs in Bobicho Kebele was 
TABLE 2: Behaviour- and environment-related characteristics of study participants in Hosanna town, 2019/2020.

\begin{tabular}{|c|c|c|c|}
\hline Variables & Categories & Number & Percent $(\%)$ \\
\hline \multirow{2}{*}{ Chat chewing } & Yes & 280 & 47.4 \\
\hline & No & 311 & 52.6 \\
\hline \multirow{2}{*}{ Alcohol consumption } & Yes & 339 & 57.4 \\
\hline & No & 252 & 42.6 \\
\hline \multirow{2}{*}{ Is your parents smoke cigarette } & Yes & 317 & 53.6 \\
\hline & No & 274 & 46.4 \\
\hline \multirow{2}{*}{ Siblings smoke cigarette } & Yes & 306 & 51.8 \\
\hline & No & 285 & 48.2 \\
\hline \multirow{2}{*}{ Peers smoke cigarette } & Yes & 366 & 61.9 \\
\hline & No & 225 & 38.1 \\
\hline \multirow{3}{*}{ Who is the role model for your cigarette smoking } & Father & 71 & 30.5 \\
\hline & Siblings & 67 & 28.8 \\
\hline & Peers & 95 & 40.8 \\
\hline \multirow{2}{*}{ Having close attachment with your families } & Yes & 339 & 57.4 \\
\hline & No & 252 & 42.6 \\
\hline \multirow{2}{*}{ During the past 30 days, did someone smoke in closed areas in your working environment } & Yes & 339 & 57.4 \\
\hline & No & 252 & 42.6 \\
\hline \multirow{2}{*}{ Cigarette accessibility } & Yes & 380 & 64.3 \\
\hline & No & 211 & 35.7 \\
\hline
\end{tabular}

5790 and in Jelo Naremo Kebele was 5490 where actual data was collected.

2.2. Study Population and Sampling. The sample size was calculated using a one population proportion formula, considering 57\% [19] proportion of individuals who smoke cigarette, 5\% margin of error and correction formula, and 5\% estimated nonresponse rate and 1.5 design effect. A multistage sampling technique was employed. From a total of 6 kebele in Hossana town (Lich-amba Kebele, Arada Kebele, Heto Kebele, J/Naremo Kebele, Bobicho Kebele, and Sech duna Kebele), 2 kebeles (Jelo/Naremo Kebele and Bobicho Kebele) were selected randomly using a lottery technique. The households were selected by systematic random sampling after determination of the Kth interval for each kebeles (Bobicho $k=10$, Jelo/Naremo $=9$ ). To select the starting household, a pen was pinned then households in the direction of the tip of the pen were selected. Finally, the starting household was selected randomly from the first $K$ th households in the direction of the tip of the pen after coding the first households 1 up to $K$ (1-10 for Bobicho and 1-9 for Jelo Naremo). The randomly selected household's number was 3 and 7 for Bobicho and Jelo/Naremo Kebeles, respectively. Then, households were selected by jumping every Kth interval. Eventually, the head of the selected household was interviewed, but in case when the household was headed by both husband and wife, female head was selected. In the absence of heads of household, the adults with age $\geq 18$ years were interviewed.

2.3. Data Collection Instrument, Data Collectors, and Data Quality Control. Data was collected using an intervieweradministered structured questionnaire. The instrument was first modified in English from earlier research conducted in the Amhara region [19] and Southern Ethiopia [20] before being translated into Hadiyisa and Amharic by language experts in Hadiyisa and Amharic and then returned to English by other language experts to guarantee consistency. The questionnaire is composed of socio demographic characteristics, behaviour-related characteristics, and environment related characteristics of respondent. Eight diploma nurses as data collectors and four BSc in health as supervisors were employed. Data collectors and supervisors received two days of training from the lead investigator to assure the quality of the field operation. The supervisors had overseen the data collection procedure on a daily basis and performed quality checks during the data collection. To ensure the tool's dependability, it was pretested on $5 \%$ of the sample before the real data collection days in Gibe Woreda, which is 30 kilometers away from the study area. The questionnaire was not changed based on the findings and input gathered during the pretesting procedure. The main data analysis did not contain the pretested data. During the data collection process, participants were able to choose acceptable locations.

2.4. Data Processing and Analysis. Before entering the data into the software, all of the data was carefully validated. The data was then entered into the Epi Data version 3.1 software on a computer. The software was built with data types and sizes in mind, as well as categories, validating permissible values and ranges, and codes for missing values. For each of the variables, descriptive analysis was used to verify frequency, distribution, and missing values. To see if there was a direct link between cigarette smoking and the independent variables, bivariate analysis was used. The Chi- 
TABLE 3: Bivariable analysis of factors associated with cigarette smoking among residents in Hossana town, 2019/2020.

\begin{tabular}{|c|c|c|c|c|c|}
\hline \multirow{2}{*}{ Variable } & \multirow{2}{*}{ Category } & \multicolumn{2}{|c|}{ Cigarette smoking } & \multirow{2}{*}{ COR $(95 \% \mathrm{CI})$} & \multirow{2}{*}{$p$ value } \\
\hline & & Yes & No & & \\
\hline \multirow{2}{*}{ Sex } & Male & $168(28.4 \%)$ & $336(56.9 \%)$ & $8.2(0.030,0.191)$ & $<0.001$ \\
\hline & Female & $5(0.8 \%)$ & $82(13.9 \%)$ & 1 & \\
\hline \multirow{4}{*}{ Family size } & $1-3$ & $8(1.4 \%)$ & $157(26.6 \%)$ & $0.082(0.031,0.222)$ & $<0.001$ \\
\hline & $4-6$ & $139(33.0 \%)$ & $208(25.7 \%)$ & $2.072(1.005,4.272)$ & 0.048 \\
\hline & $7-8$ & $13(2.2 \%)$ & $32(5.4 \%)$ & $0.656(0.255,1.689)$ & 0.383 \\
\hline & $\geq 8$ & $13(2.2 \%)$ & $21(3.6 \%)$ & 1 & \\
\hline \multirow{5}{*}{ Occupation } & Daily laborer & $60(10.2 \%)$ & $157(26.6 \%)$ & 1 & \\
\hline & Gov't employed & $60(10.2 \%)$ & $148(25.0 \%)$ & $3.299(2.202,4.943)$ & $<0.001$ \\
\hline & Self-employed & $19(3.2 \%)$ & $53(9.0 \%)$ & $0.938(0.513,1.714)$ & 0.835 \\
\hline & Merchant & $31(5.2 \%)$ & $49(8.3 \%)$ & $1.655(0.965,2.839)$ & 0.067 \\
\hline & Other & $3(0.5 \%)$ & $11(1.9 \%)$ & $0.714(0.192,2.647)$ & 0.614 \\
\hline \multirow{3}{*}{ Educational status } & Illiterate & $8(1.4 \%)$ & $153(25.9 \%)$ & $0.071(0.030,0.171)$ & $<0.001$ \\
\hline & $\leq 12$ grade & $140(23.7 \%)$ & $231(39.1 \%)$ & $1.523(0.874,2.654)$ & 0.137 \\
\hline & $\geq$ College & $25(4.2 \%)$ & $34(5.8 \%)$ & 1 & \\
\hline \multirow{5}{*}{ Monthly income } & $0-1500$ & $55(9.3 \%)$ & $28(4.7 \%)$ & 1 & \\
\hline & $1501-3000$ & $6(1.0 \%)$ & $79(13.4 \%)$ & $0.039(0.015,0.100)$ & $<0.001$ \\
\hline & $3001-4500$ & $74(12.5 \%)$ & $82(13.9 \%)$ & $0.459(0.264,0.799)$ & 0.006 \\
\hline & $4501-6000$ & $14(2.4 \%)$ & $74(12.5 \%)$ & $0.096(0.046,0.200)$ & $<0.001$ \\
\hline & $\geq 6001$ & $24(4.1 \%)$ & $155(26.2 \%)$ & $0.411(0.239,0.707)$ & 0.001 \\
\hline \multirow{2}{*}{ Khat chewing } & Yes & $81(13.7 \%)$ & $258(43.7 \%)$ & $0.221(0.155,0.314)$ & $<0.001$ \\
\hline & No & $92(15.6 \%)$ & $160(27.1 \%)$ & 1 & \\
\hline \multirow{2}{*}{ Alcohol consumption } & Yes & $81(13.7 \%)$ & $258(43.7 \%)$ & 1 & \\
\hline & No & $92(15.6 \%)$ & $160(27.1 \%)$ & $4.533(3.182,6.457)$ & $<0.001$ \\
\hline \multirow{2}{*}{ Is your parents smoke cigarette } & Yes & $72(12.2 \%)$ & $245(41.5 \%)$ & 1 & \\
\hline & No & $101(17.1 \%)$ & $173(29.3 \%)$ & $4.565(3.200,6.515)$ & $<0.001$ \\
\hline \multirow{2}{*}{ Siblings smoke cigarette } & Yes & $73(12.4 \%)$ & $233(39.4 \%)$ & 1 & \\
\hline & No & $156(26.4 \%)$ & $129(21.8 \%)$ & $3.860(2.716,5.485)$ & $<0.001$ \\
\hline \multirow{2}{*}{ Peers smoke cigarette } & Yes & $95(16.1 \%)$ & $271(45.9 \%)$ & 1 & \\
\hline & No & $78(13.2 \%)$ & $147(24.9 \%)$ & $4.201(2.948,5.986)$ & $<0.001$ \\
\hline \multirow{2}{*}{ Cigarette accessibility } & Yes & $102(17.3 \%)$ & $278(47.0 \%)$ & 1 & \\
\hline & No & $71(12.0 \%)$ & $140(23.7 \%)$ & $4.121(2.883,5.889)$ & $<0.001$ \\
\hline
\end{tabular}

square test was used to see if the variables met the assumptions. To find the factors that affect the prevalence of cigarette smoking, a variable with a $p$ value of 0.25 on bivariate analysis was incorporated into multivariable logistic regression. The degrees of relationship between the independent variable and cigarette smoking status were quantified using the odds ratio and 95 percent confidence intervals. The results with a $p$ value of less than 0.05 were declared statistically significant, while the remainder was disproved. The multicollinearity diagnostic test VIF in linear regression was used to assess for collinearity among independently related variables, and none were found to be collinear.

\section{Result}

3.1. Socio-Demographic-Related Characteristics. Overall 591 participants were participated in this study which makes a response rate of $93.8 \%$. From study participants, 261 (44.2\%) were $18-27$ years old, $504(85.3 \%)$ of the participants were males, 408 (69.0\%) were married, 347 (58.7\%) have 4-6 family size, 269 (45.5\%) were protestant, 251 (42.5\%) were Hadiya, 217 (36.7\%) were daily laborer, 371 (62.8\%) were $\leq 12$ grade educational status, and 155 (26.2\%) have 30014500 monthly income (Table 1$)$.

3.2. Prevalence of Cigarette Smoking. From the study participants, 183 (31.0\%) were cigarette smokers (see Figure 1).

3.3. Behaviour- and Environment-Related Characteristics. From study participants, 280 (47.4\%) were Khat chewers, 339 (57.4\%) were alcohol drinkers, 317 (53.6\%) were having cigarette smoker parents, 306 (51.8\%) were having cigarette smoking siblings, and $366(61.9 \%)$ were having cigarette smoking peers (Table 2). 
TABLE 4: Multivariable analysis of factors associated with cigarette smoking among study participants in Hossana town, $2019 / 20$.

\begin{tabular}{|c|c|c|c|c|c|c|}
\hline \multirow{2}{*}{ Variable } & \multirow{2}{*}{ Category } & \multicolumn{2}{|c|}{ Cigarette smoking } & \multirow{2}{*}{ COR $(95 \% \mathrm{CI})$} & \multirow{2}{*}{$\operatorname{AOR}(95 \% \mathrm{CI})$} & \multirow{2}{*}{$p$ value } \\
\hline & & Yes & No & & & \\
\hline \multirow{4}{*}{ Family size } & $1-3$ & $8(1.4 \%)$ & $157(26.6 \%)$ & $0.082(0.031,0.222)$ & $0.873(0.912,6.139)$ & 0.645 \\
\hline & $4-6$ & $139(33.0 \%)$ & $208(25.7 \%)$ & $2.072(1.005,4.272)$ & $0.944(0.413,2.161)$ & 0.892 \\
\hline & $7-8$ & $13(2.2 \%)$ & $32(5.4 \%)$ & $0.656(0.255,1.689)$ & $0.644(0.233,1.782)$ & 0.392 \\
\hline & $\geq 8$ & $13(2.2 \%)$ & $21(3.6 \%)$ & 1 & 1 & \\
\hline \multirow{5}{*}{ Occupation } & Daily laborer & $60(10.2 \%)$ & $157(26.6 \%)$ & 1 & 1 & \\
\hline & Gov't employed & $60(10.2 \%)$ & $148(25.0 \%)$ & $3.299(2.202,4.943)$ & $0.017(0.005,8.153)$ & 0.567 \\
\hline & Self-employed & $19(3.2 \%)$ & $53(9.0 \%)$ & $0.938(0.513,1.714)$ & $0.028(0.009,3.184)$ & 0.312 \\
\hline & Merchant & $31(5.2 \%)$ & $49(8.3 \%)$ & $1.655(0.965,2.839)$ & $0.007(0.001,1.039)$ & 0.154 \\
\hline & Other & $3(0.5 \%)$ & $11(1.9 \%)$ & $0.714(0.192,2.647)$ & $0.017(0.006,2.051)$ & 0.241 \\
\hline \multirow{5}{*}{ Monthly income } & $0-1500$ & $55(9.3 \%)$ & $28(4.7 \%)$ & 1 & 1 & \\
\hline & $1501-3000$ & $6(1.0 \%)$ & $79(13.4 \%)$ & $0.039(0.015,0.100)$ & $1.224(0.881,17.533)$ & 0.432 \\
\hline & $3001-4500$ & $74(12.5 \%)$ & $82(13.9 \%)$ & $0.459(0.264,0.799)$ & $0.331(0.664,1.311)$ & 0.231 \\
\hline & $4501-6000$ & $14(2.4 \%)$ & $74(12.5 \%)$ & $0.096(0.046,0.200)$ & $0.977(0.564,2.332)$ & 0.114 \\
\hline & $\geq 6001$ & $24(4.1 \%)$ & $155(26.2 \%)$ & $0.411(0.239,0.707)$ & $0.675(0.977,1.871)$ & 0.224 \\
\hline \multirow{3}{*}{ Educational status } & Illiterate & $8(1.4 \%)$ & $153(25.9 \%)$ & $0.071(0.030,0.171)$ & $9.058(3.652,22.469)$ & $<0.001^{* *}$ \\
\hline & $\leq 12$ grade & $140(23.7 \%)$ & $231(39.1 \%)$ & $1.523(0.874,2.654)$ & $0.646(0,367,1.139)$ & 0.131 \\
\hline & $\geq$ College & $25(4.2 \%)$ & $34(5.8 \%)$ & 1 & 1 & \\
\hline \multirow{2}{*}{ Chat chewing } & Yes & $81(13.7 \%)$ & $258(43.7 \%)$ & $0.221(0.155,0.314)$ & $0.664(0.222,1.986)$ & 0.464 \\
\hline & No & $92(15.6 \%)$ & $160(27.1 \%)$ & 1 & 1 & \\
\hline \multirow{2}{*}{ Is your parents smoke cigarette } & Yes & $72(12.2 \%)$ & $245(41.5 \%)$ & 1 & 1 & \\
\hline & No & $157(26.6 \%)$ & $117(19.8 \%)$ & $4.565(3.200,6.515)$ & $2.288(1.548,3.383)$ & $<0.001^{* *}$ \\
\hline \multirow{2}{*}{ Siblings smoke cigarette } & Yes & $73(12.4 \%)$ & $233(39.4 \%)$ & 1 & 1 & \\
\hline & No & $156(26.4 \%)$ & $129(21.8 \%)$ & $3.860(2.716,5.485)$ & $0.847(0.339,2.118)$ & 0.722 \\
\hline \multirow{2}{*}{ Peers smoke cigarette } & Yes & $95(16.1 \%)$ & $271(45.9 \%)$ & 1 & & \\
\hline & No & $134(22.7 \%)$ & $91(15.4 \%)$ & $4.201(2.948,5.986)$ & $1.472(0.658,3.297)$ & 0.347 \\
\hline \multirow{2}{*}{ Cigarette accessibility } & Yes & $102(17.3 \%)$ & $278(47.0 \%)$ & 1 & 1 & \\
\hline & No & $127(60.2 \%)$ & $84(14.2 \%)$ & $4.121(2.883,5.889)$ & $2.354(0.117,5.980)$ & 0.921 \\
\hline \multirow{2}{*}{ Alcohol consumption } & Yes & $81(13.7 \%)$ & $258(43.7 \%)$ & $4.533(3.182,6.457)$ & $2.320(1.331,8.440)$ & $0.004^{*}$ \\
\hline & No & $148(25.0 \%)$ & $104(17.6 \%)$ & 1 & 1 & \\
\hline
\end{tabular}

3.4. Bivariable Analysis of Factors Linked to Cigarette Smoking. Sex, family size, occupation, educational status, monthly income, khat chewing, alcohol use, parental cigarette smoking, siblings' cigarette smoking, peers' cigarette smoking, and cigarette accessibility were all eligible for multivariable analysis (Table 3 ).

3.5. Factors Associated with Cigarette Smoking in Multivariable Logistic Regression. Educational status, alcohol use, and parental smoking were all found to have a significant relationship with cigarette smoking among research participants in Hosanna town. This finding revealed that illiterates are nearly nine times $\mathrm{AOR}$ at $95 \% \mathrm{CI}=9.058$ $(3.652,22.469)$ smoke cigarette when compared to individuals with college and above. Alcohol drinkers are nearly two times AOR at $95 \% \mathrm{CI}=2.288(1.548,3.383)$ smoke cigarette than their counter parts. Those individuals having cigarette smoking parents are nearly two times AOR at $95 \%$ $\mathrm{CI}=2.288(1.548,3.383)$ smoke cigarette than their counter parts (Table 4 ).

\section{Discussion}

The overall prevalence of cigarette smoking was 31.0 percent, according to the result of this research. This study's prevalence is similar to that of studies conducted in China (31.8\%) [21] and Tunisia (30.4\%) [22]. This result was higher than those of studies conducted in Eastern Ethiopia (28\%) [23], Madagascar (28.5\%) [24], Bangladesh (23.19\%) [25], and Misrak Badewacho (23.6\%) [20]. This result was lower than those found in Jimma Town (35.5\%) [26] and Amhara area (57.0\%) studies [19]. This disparity could be attributable to socioeconomic and cultural inequalities, as well as variances in study settings. In this study, the prevalence of cigarette smoking is higher among males than females, among drinkers against nondrinkers, among those with smoking peers versus nonsmokers, and among those with cigarette access versus nonsmokers.

In this study, educational status, particularly illiteracy, was found to be substantially related with cigarette smoking. Various conclusions have been published in earlier studies 
regarding the relationship between educational status and cigarette smoking. This finding was supported with previously conducted in Uttar Pradesh [27], Jimma [28], Helaba [16], and low and middle income countries [21, 29, 30]. It is possible that the link between illiteracy and cigarette smoking is due to a lack of knowledge regarding tobacco's harmful effects on health.

This study finding revealed that alcohol drinking has significant association with cigarette smoking. This finding was supported with previously conducted in Nigeria [31]. This observed association might be due to the consumption of alcohol that also triggers the probability of having cigarette smoking.

Also, this study finding revealed that those having parental cigarette smoking have significant association with cigarette smoking. This finding has been supported by study conducted in China [32-34] and in Sudan [35]. The possible reason for this observed association could be taking parents as their role model and passing extended time and intact contact with parents.

\section{Conclusion and Recommendation}

The prevalence of cigarette smoking among residents in the Hossana town is high. Furthermore, cigarette smoking was found to be substantially linked to illiteracy, alcohol consumption, and parental smoking in this study. The zonal health department, woreda health office, and health facilities should focus on regular surveys on prevalence and determinants of all forms of tobacco use in the general population and adjusting outreach session program for health professionals and health extension workers as much as possible. The researchers are recommended to conduct further research on cigarette smoking with strong epidemiological design to overcome the limitation of this study.

\section{Strength and Limitations}

This study looks into the prevalence of cigarette smoking and related factors in adult age groups that are rarely looked into. Because this study is based on self-report, the prevalence of cigarette smoking may be under- or overreported.

\section{Abbreviations}

AOR: Adjusted odds ratio

COR: Crude odds ratio

FCTC: Framework Convention on Tobacco Control

SPSS: Statistical Package for the Social Sciences

WHO: World Health Organization.

\section{Data Availability}

The data that supports the findings of this study are available; however, due to some sensitive problems, there may be some restrictions on their use. However, upon reasonable request, data can be obtained from the respective author.

\section{Ethical Approval}

After receiving approval from Wachemo University College of Medicine and Health Sciences Ethical Committee, the data was collected.

\section{Consent}

Following an explanation of the study's goal, study volunteers were asked to participate voluntarily. All data gathered from study participants was kept strictly secret. To take part in this study, all individuals gave their informed consent.

\section{Conflicts of Interest}

The authors declare that they have no competing interests.

\section{Authors' Contributions}

$\mathrm{AB}$ led the conception, methods, validation, analysis, fund securing, and manuscript preparation, while TT, TE, FE, EA, AM, LA, DS, TT, and DE participated in data analysis, methods, statistical techniques, and manuscript preparation. The final version of this work has been read and approved by all of the authors. All authors contributed significantly to the conception and design, data acquisition, and data analysis and interpretation; participated in the drafting of the article or critically revised it for important intellectual content; agreed to submit to the current journal; gave final approval of the version to be published; and agreed to be accountable for all aspects of the work.

\section{Acknowledgments}

The authors would like to express their gratitude to Wachemo University for allowing them to conduct this research. We would like to thank the supervisors and data collectors for their dedication during the data collection process. We would also like to express our gratitude to respondents for their willingness to provide critical data for the study. The Wachemo University College of Medicine and Health Sciences provided funding for this research.

\section{References}

[1] C. D. Mathers and D. Loncar, "Projections of global mortality and burden of disease from 2002 to 2030," PLoS Medicine, vol. 3, no. 11, p. e442, 2006.

[2] WHO, WHO recommendations for the prevention and management of tobacco use and second-hand smoke exposure in pregnancy, WHO, 1211 Geneva 27,Switzerland, 2013.

[3] WHO, WHO report on the global tobacco epidemic, the MPOWER package, World health organization, Geneva, Switzerland, 2008.

[4] WHO, WHO report on the global tobacco epidemic, 2013: enforcing bans on tobacco advertising, promotion and sponsorship, WHO, 1211 Geneva 27, Switzerland, 2013.

[5] R. C. McMillen, J. P. Winickoff, J. D. Klein, and M. Weitzman, "US adult attitudes and practices regarding smoking restrictions and child exposure to environmental tobacco smoke: 
changes in the social climate from 2000-2001," Pediatrics, vol. 112, no. 1, pp. e55-e60, 2003.

[6] G. A. Giovino, S. A. Mirza, J. M. Samet et al., "Tobacco use in 3 billion individuals from 16 countries: an analysis of nationally representative cross-sectional household surveys," Lancet, vol. 380, no. 9842, pp. 668-679, 2012.

[7] International Agency for Research on Cancer, IARC monographs on the evaluation of carcinogenic risks to humans: a review of human carcinogens: personal habits and indoor combustions, p. 100, 2010.

[8] J. Leonardi-Bee, M. L. Jere, and J. Britton, "Exposure to parental and sibling smoking and the risk of smoking uptake in childhood and adolescence: a systematic review and metaanalysis," Thorax, vol. 66, no. 10, pp. 847-855, 2011.

[9] WHO, WHO Report on the Global Tobacco Epidemic, 2011: Warning about the Dangers of Tobacco, WHO, 1211 Geneva 27, Switzerland, 2011.

[10] Commonwealth of Australia 2012, National Tobacco Strategy 2012-2018 Australia, 2012.

[11] P. M. Lantz, P. D. Jacobson, K. E. Warner et al., "Investing in youth tobacco control: a review of smoking prevention and control strategies," Tobacco Control, vol. 9, no. 1, pp. 47-63, 2000.

[12] L. Mo-suwan and A. Ma-a-lee, "Prevalence and associated factors of passive smoking in Thai infants," Preventive Medicine, vol. 47, no. 4, pp. 443-446, 2008.

[13] S. J. Slater, F. J. Chaloupka, M. Wakefield, L. D. Johnston, and P. M. O'Malley, "The impact of retail cigarette marketing practices on youth smoking uptake," Archives of Pediatrics \& Adolescent Medicine, vol. 161, no. 5, pp. 440-445, 2007.

[14] F. A. Okah, W. S. Choi, K. S. Okuyemi, and J. S. Ahluwalia, "Effect of children on home smoking restriction by inner-city smokers," Pediatrics, vol. 109, no. 2, pp. 244-249, 2002.

[15] K. K. Aryal, S. Mehata, S. Neupane et al., "The burden and determinants of Non Communicable diseases risk factors in Nepal: findings from a nationwide STEPS survey," PLoS One, vol. 10, no. 8, article e0134834, 2015.

[16] T. Ketema, E. Alemayehu, and A. Ambelu, "Exploration of pattern of use of Khat and tobaccoamong residents of Halaba Kulito Town, Southern Ethiopia," The Journal of Biological Chemistry, vol. 32, no. 1, pp. 374-386, 2015.

[17] K. M. Emmons, D. B. Abrams, R. J. Marshall et al., "Exposure to environmental tobacco smoke in naturalistic settings," American Journal of Public Health, vol. 82, no. 1, pp. 24-28, 1992.

[18] WHO, WHO Framework Convention on Tobacco Control: Guidelines for Implementation, WHO Library Cataloguingin-Publication Data, 1211 Geneva 27, Switzerland, 2013.

[19] A. S. Tegegne, "Assessing public awareness about the health effects of nicotine and cigarettes using negative binomial regression," Science Journal of Applied Mathematics and Statistics, vol. 2, no. 3, pp. 60-65, 2014.

[20] T. M. Lodebo, K. W. Hajito, T. T. Gebrehiwot, and T. B. Achicha, "Prevalence of cigarette smoking and its associated factors among parents at Misrak Bedawacho District, Southern Ethiopia," Journal of addiction and prevention, vol. 5, no. 1, pp. 1-9, 2017.

[21] Z. Li, Y. Yao, W. Han et al., "Smoking prevalence and associated factors as well as Attitudes and perceptions towards tobacco control in Northeast China," International journal of environmental research and public health, vol. 12, no. 7, pp. 8606-8618, 2015.
[22] F. Pampel, "Tobacco use in sub-Sahara Africa: estimates from the demographic health surveys. keniya," Scientia Medica, vol. 66, pp. 1772-1783, 2008.

[23] A. A. Reda, D. Kotz, and S. Biadgilign, "Adult tobacco use practice and its correlates in eastern Ethiopia: a crosssectional study," Harm Reduction Journal, vol. 10, p. 28, 2013.

[24] C. T. Sreeramareddy, P. Pradhan, and S. Sin, "Prevalence, distribution, and social determinants of tobacco use in 30 subSaharan African countries," BMC medicine, vol. 12, no. 1, p. 243, 2014.

[25] P. Sultana, S. Akter, M. M. Rahman, and M. S. Alam, "Prevalence and predictors of current tobacco smoking in Bangladesh," Journal of Biostatistics and Biometric Applications, vol. 1, no. 1, p. 102, 2016.

[26] B. Sisay, M. Andualem, and G. Teshome, "Prevalence of hypertension and its association with substance use among adults living in Jimma Town, South West Ethiopia," World Journal of Medicine and Medical Science, vol. 2, no. 1, 2014.

[27] S. Dixit, M. A. Ansari, Z. Khan, and N. Khalique, "Prevalence and predictors of Tobacco use: a cross-sectional household survey in Aligarih District of Uttar Pradesh," Indian journal of community health, vol. 24, no. 3, 2012.

[28] Y. Lakew and D. Haile, "Tobacco use and associated factors among adults in Ethiopia: further analysis of the 2011 Ethiopian Demographic and Health Survey," BMC Public Health, vol. 15, p. 487, 2015.

[29] K. M. Palipudi, P. C. Gupta, D. N. Sinha et al., "Social determinants of health and tobacco use in thirteen low and middle income countries: evidence from Global Adult Tobacco Survey," PLoS One, vol. 7, no. 3, article e33466, 2012.

[30] A. R. Hosseinpoor, L. A. Parker, E. Tursan d'Espaignet, and S. Chatterji, "Socioeconomic inequality in smoking in lowincome and middle-income countries: results from the World Health Survey," PLoS One, vol. 7, no. 8, p. e42843, 2012.

[31] F. Eniojukan Joshua and A. Owonaro Peter, "Prevalence and contexts of smoking among the people of Kaiama community in Bayelsa State, Nigeria," Practical nursing for male nurses in the R A M C and other forces, vol. 4, no. 1, pp. 52-62, 2016.

[32] M. Wang, J.-M. Zhong, L. Fang, and H. Wang, "Prevalence and associated factors of smoking in middle and high school students: a school-based cross-sectional study in Zhejiang Province, China," BMJ Open, vol. 6, no. 1, article e010379, 2016.

[33] B. Xie, P. Palmer, Y. Li, C. Lin, and C. A. Johnson, "Developmental trajectories of cigarette use and associations with multilayered risk factors among Chinese adolescents," Nicotine \& Tobacco Research, vol. 15, no. 10, pp. 1673-1681, 2013.

[34] A. S. Licht, B. A. King, M. J. Travers, C. Rivard, and A. J. Hyland, "Attitudes, experiences, and acceptance of smokefree policies among US multiunit housing residents," American Journal of Public Health, vol. 102, no. 10, pp. 1868-1871, 2012.

[35] R. J. Mashita, M. J. Themane, K. D. Monyeki, and H. C. G. Kemper, "Current smoking behaviour among rural South African children: Ellisras Longitudinal Study," BMC Pediatrics, vol. 11, no. 1, p. 58, 2011. 